УДК 616.366-003.7-06-072.1-089.819

DOI 10.11603/2414-4533.2019.1.9911

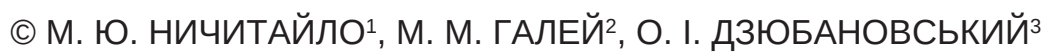

Національний інститут хірургії та трансплантології імені О. О. Шалімова ${ }^{1}$

Волинська обласна клінічна лікарня²

ДВНЗ “Тернопільський державний медичний університет імені І. Я. Горбачевського МОЗ України”з

\title{
Порівняльна оцінка ефективності розробленого одномоментного лапароскопічного лікування жовчнокам'яної хвороби та супутньої хірургічної патології
}

\begin{abstract}
Мета роботи: визначити максимально ефективну технологію візуалізації при виконанні лапароскопічного операційного лікування жовчнокам'яної хвороби та супутньої хірургічної патології.

Матеріали і методи. Використано статистичні дані щодо лікування 411 хворих із ЖКХ та супутньою хірургічною патологією. Для обробки статистики використовували методи з нульовою гіпотезою. Для порівняння визначали зону візуалізації. Для порівняння використано власний метод і французький метод виконання лапароскопічної холецистектомії.

Результати досліджень та їх обговорення. За результатами дослідження встановлено, що оцінене маргінальне середнє значення площі зони візуалізації при власному способі симультанних операційних втручань становить $(15,24 \pm 3,76) \mathrm{cm}^{2} \mathrm{i}$ більше на 62,6 \% від відповідного показника французького способу - $(9,54 \pm 2,27)$ см² $(p=0,715)$; при застосуванні лапароскопа 3 кутом спостереження $0{ }^{\circ}$ відстань наближення лапароскопа при власному способі доступу в середньому становить $(3,81 \pm 0,52)$ см і більше на 10,5 \% порівняно з середнім значенням досліджуваного параметра при французькому способі $(3,41 \pm 0,478)$ см $(\mathrm{p}=0,295)$; при застосуванні лапароскопа з кутом спостереження 30 відстань наближення лапароскопа при власному способі доступу в середньому становить $(3,64 \pm 0,36)$ см і більше на $9,12 \%$ порівняно з показником французького способу - $(3,34 \pm 0,728)$ см $(\mathrm{p}<0,001)$.
\end{abstract}

Ключові слова: хірургія; холецистектомія; жовчнокам’яна хвороба; лапароскопія; симультанні втручання.

Постановка проблеми і аналіз останніх досліджень та публікацій. На даний момент 30 \% від усіх хірургічних патологій дорослого населення Європи складає жовчнокам'яна хвороба (ЖКХ). У 20 \% випадків холедохолітіаз є ускладненням ЖКХ. У 14 \% хворих наявна супутня хірургічна патологія. У роботі проведено аналіз методів лікування ЖКХ із холедохолітіазом і супутньою хірургічною патологією [1-3].

Наводимо дані щодо операційного лікування хворих шляхом виконання симультанних операційних втручань, напрацьовані в умовах відділення інвазивних методів діагностики та лікування Волинської обласної клінічної лікарні (ВІМДЛ ВОКЛ). Також у роботі проводиться порівняння ефективності, безпеки, швидкості та етапності, а також доцільність одноетапного підходу в лікуванні ЖКХ.

Мета роботи: порівняння власного способу виконання симультанних операційних втручань із французьким за доступністю до об'єкта операції, можливостями візуалізації зони операції та ергономічними умовами її виконання. Дані про франзуцький метод виконання отримано $з$ наукових публікацій про клінічну роботу наших колег [13].

Матеріали і методи. Дані про пацієнтів, результати лабораторних та інструментальних методів дослідження, а також результати операцій- них втручань занесено в карти обстеження людей (типова форма журналу, затверджена у Тернопільському державному медичному університеті імені І. Я. Горбачевського). На основі карт створено електронну базу даних пацієнтів. Для введення даних застосовували програму Microsoft Office Excel 2010 SP1 (Microsoft corp., 2010). 3a допомогою функції YEARFRAC (поч_дата;кін_ дата;базис) в Excel визначали й вік пацієнтів на момент госпіталізації [4-7].

Статистичний аналіз результатів дослідження проводили з використанням програми SPSS 16.0.1 for Windows (SPSS Inc., Chicago, IL, USA). За допомогою програми здійснювали структурування, перевірку даних, дескриптивний аналіз та аналітичну статистику. Статистичну обробку даних проводили згідно зі статистичними рекомендаціями від 21.11.2008 р. загальновідомого рейтингового періодичного видання «Nature medicine».

Про відсутність взаємозв'язку або кореляції між досліджуваними змінними, значущих відмінностей у розподілах вибірок, впливу факторів на змінну при використанні аналітичних методів статистики приймалась гіпотеза (нульова). Застосовували для перевірки гіпотези про нормальний розподіл змінних величин за допомогою теста Колмогорова-Смірнова. Взаємозв'язок між змінними вивчали за допомогою кореляційного аналізу за Пірсоном. Застосовували рангову кореля- 


\section{З ДОСВІДУ РОБОТИ}

цію за Спірманом у випадку, коли хоча б одна зі змінних мала порядкову шкалу або не була розподілена. Для змінних величин, які належать до інтервальної шкали та підпорядковуються нормальному розподілу, визначали середнє значення та стандартне відхилення. Для порівняння середніх значень застосовували t-тест для незалежних вибірок, а також t-тест для парних вибірок з 95 \% довірчим інтервалом різниці середніх. Процедуру порівняння середніх значень трьох зв’язаних вибірок здійснювали шляхом дисперсійного аналізу з повторними вимірюваннями, а також багатомірного дисперсійного аналізу (MANOVA). При цьому використовували апостеріорні тести: критерій Тьюкі та LSD-тест (найменша значуща різниця). У випадку, коли дані не підпорядковувались нормальному розподілу, визначали медіану, нижній і верхній квартилі та застосовували непараметричний U-тест Манна-Уїтні. Для порівняння категоріальних даних застосовували $\chi^{2}$-тест, а також U-тест Манна-Уїтні. Визначали двосторонній рівень значущості. Прийнятною межею статистичної значущості вважали рівень $\mathrm{p} \leq 0,05$ [8-12]. Результати з рівнем $\mathrm{p} \leq 0,01$ розглядали як статистично значущі, з рівнем $\mathrm{p} \leq 0,001$ - як високо значущі. Дослідження проведено на базі Волинської обласної клінічної лікарні в умовах відділення інвазивних методів діагностики та лікування та на базі ФПО ДВНЗ “Тернопільський державний медичний університет імені І. Я. Горбачевського”.

За ділянку операційної дії визначено сектор круга (обмежений передньою черевною стінкою та частково діафрагмою) на площині вісцеральної поверхні печінки, центром якого є крайня верхня точка на дні жовчного міхура, а радіусом - відстань між робочими кінцями інструментів, якими здійснюється операційний вплив.

Результати досліджень та їх обговорення. При аналізі статистичних даних, отриманих після обробки наших показників, викорисовуючи кореляцію за Пірсоном та багатомірний дисперсійний аналіз можна побачити, що наш власний метод виконання симультанних лапароскопічних операції при поєднанні ЖКХ та іншої хірургічної патології не відрізняється від стандартного французького методу виконання лапароскопічної холецистектомії за комфортом, при цьому забезпечує більшу область візуалізації, а також дозволяє хірургу та асистенту працювати в більш комфортних умовах, не входячи в неергономічні положення, що збільшують рівень психоемоційного та фізичного напруження. Наш власний метод введення портів для виконання симультанних операційних втручань дозволяє знизити втому після операції на хірургічну бригаду порівняно із звичайним французьким методом.

В умовах експерименту вивчали площу візуалізацї; відстань між центрами кистей хірурга, який маніпулює одночасно двома інструментами; відстань наближення лапароскопа до операційної ділянки та кут між основними робочими інструментами. При цьому площа візуалізації та відстань між центрами кистей хірурга, який маніпулює одночасно двома інструментами, а також рівень психоемоційної втоми - нові критерії оцінки параметрів операційного доступу, що характеризують якість доступу та ергономічні умови виконання лапароскопічної операції.

Площа візуалізації - частина площі операційної ділянки, яка повністю доступна для впливу та візуального контролю хірурга.

Відстань між центрами кистей хірурга, який здійснює бімануальні маніпуляцї̈, при французькому та власному способах, це - максимальна дистанція між центрами кистей за умов здійснення операційного впливу. При власному способі визначалась відстань між центрами кистей хірурга-асистента.

Проект дослідження передбачав визначення площі зони візуалізації, відстані між центрами кистей хірурга, який здійснює бімануальні маніпуляції, відстані наближення лапароскопа до операційної ділянки та кута між основними робочими інструментами у двох групах - відповідно до способу симультанного операційного втручання: I група французький спосіб, II група - власний спосіб. Для кожного способу досліджувані параметри визначали у трьох підгрупах, які відрізнялись розташуванням портів - відповідно до нормостенічного, гіперта астенічного типів статури. При цьому різниця відстані між портами для гіперстенічного та астенічного типів при французькому способі становила 4,5 см, а при власному способі - 3,1 см.

Для виконання експерименту використовували ендовідеосистему MGB, лапароскопи з кутом спостереження $0^{\circ}$ та $30^{\circ}$ та лапароскопічні інструменти фірми Karl Storz.

Результати дослідження вказують на те, що зона візуалізації об’єкта операції зростає зі збільшенням свободи руху лапароскопа і відсутністю фехтування (табл. 1).

Отже, результати статистичного аналізу свідчать, що для кожного зі способів симультанного операційного втручання збільшення чи зменшення відстані між портами, залежно від типу статури, не впливає на доступність до об’єкта операції.

Таким чином, відстань між портами, а, отже, й кут між основними робочими інструментами, суттєво не погіршують умови доступності до цільового органа. Підтвердженням цього є і той факт, 
Таблиця 1. Показники досліджуваних параметрів та результати статистичного аналізу

\begin{tabular}{|c|c|c|c|c|c|c|c|}
\hline \multirow{2}{*}{\multicolumn{2}{|c|}{$\begin{array}{c}\text { Спосіб лапароскопічної } \\
\text { холецистектомії } \\
\text { Тип статури }\end{array}$}} & \multicolumn{3}{|c|}{ Французький } & \multicolumn{3}{|c|}{ Власний } \\
\hline & & Нормост. & Гіперст. & Астен. & Нормост. & Гіперст. & Астен. \\
\hline \multirow{2}{*}{$\begin{array}{l}\text { Кореляція } \\
\text { за Пірсоном } \\
\text { у підгрупах } \\
\text { (двосторонній } \\
\text { рівень значущості) }\end{array}$} & Гіперст. & $\begin{array}{c}\mathrm{r}=0,957^{* *} ; \\
\mathrm{p}<0,001\end{array}$ & - & - & $\begin{array}{c}\mathrm{r}=0,992^{* *} ; \\
\mathrm{p}<0,001\end{array}$ & - & - \\
\hline & Астен. & $\begin{array}{c}\mathrm{r}=0,982 * * \\
\mathrm{p}<0,001\end{array}$ & $\begin{array}{c}\mathrm{r}=0,989 * * ; \\
\mathrm{p}<0,001\end{array}$ & - & $\begin{array}{c}\mathrm{r}=0,993^{* *} ; \\
\mathrm{p}<0,001\end{array}$ & $\begin{array}{c}\mathrm{r}=0,997^{* *} ; \\
\mathrm{p}<0,001\end{array}$ & - \\
\hline $\begin{array}{l}\text { Багатомірний } \\
\text { дисперсійний аналіз } \\
\text { (MANOVA) }\end{array}$ & & \multicolumn{3}{|c|}{$\mathrm{p}=0,971$} & \multicolumn{3}{|c|}{$\mathrm{p}=0,990$} \\
\hline $\begin{array}{l}\text { Кут між основними } \\
\text { маніпуляторами } \\
\text { град. }(\mathrm{n}=14)\end{array}$ & $\begin{array}{l}(\mathrm{M} \pm \mathrm{SD}) \\
\text { Min-max }\end{array}$ & $\begin{array}{c}57,29 \pm 6,764 \\
44-65\end{array}$ & - & - & $\begin{array}{c}74,43 \pm 8,112 \\
66-83\end{array}$ & - & - \\
\hline $\begin{array}{l}\text { Відстань між } \\
\text { центрами кистей } \\
\text { хірурга, см }(\mathrm{n}=25)\end{array}$ & $\begin{array}{l}(\mathrm{M} \pm \mathrm{SD}) \\
\text { Min-max }\end{array}$ & $\begin{array}{c}38,08 \pm 2,8 \\
33-41\end{array}$ & $\begin{array}{c}40,94 \pm 3,02 \\
36-45\end{array}$ & $\begin{array}{c}30,50 \pm 3,42 \\
25-34\end{array}$ & $\begin{array}{c}41,22 \pm 5,63 \\
35-47\end{array}$ & $\begin{array}{c}37,52 \pm 4,11 \\
33-42\end{array}$ & $\begin{array}{c}37,12 \pm 7,05 \\
30-45\end{array}$ \\
\hline \multirow{2}{*}{$\begin{array}{l}\text { Кореляція за } \\
\text { Пірсоном } \\
\text { у підгрупах } \\
\text { (двосторонній } \\
\text { рівень значущості) }\end{array}$} & Гіперст. & $\begin{array}{c}\mathrm{r}=0,960^{* *} ; \\
\mathrm{p}<0,001\end{array}$ & - & - & $\begin{array}{c}\mathrm{r}=0,995^{* *} ; \\
\mathrm{p}<0,001\end{array}$ & - & - \\
\hline & Астен. & $\begin{array}{c}\mathrm{r}=0,953^{* *} ; \\
\mathrm{p}<0,001\end{array}$ & $\begin{array}{c}\mathrm{r}=0,986^{* *} ; \\
\mathrm{p}<0,001\end{array}$ & - & $\begin{array}{c}\mathrm{r}=0,952 * * ; \\
\mathrm{p}<0,001\end{array}$ & $\begin{array}{c}\mathrm{r}=0,963^{* *} \\
\mathrm{p}<0,001\end{array}$ & - \\
\hline \multirow{2}{*}{$\begin{array}{l}\text { Багатомірн. } \\
\text { дисперс. аналіз } \\
\text { (MANOVA), } \\
\text { критерій Тьюкі }\end{array}$} & Гіперст. & $\mathrm{p}=0,002$ & - & - & $\mathrm{p}=0,034$ & - & - \\
\hline & Астен. & $\mathrm{p}<0,001$ & $\mathrm{p}<0,001$ & - & $\mathrm{p}=0,033$ & $\mathrm{p}<0,001$ & - \\
\hline $\begin{array}{l}\text { Дистанція між } \\
\text { лапароск. } 3 \text { кутом } \\
\text { лінзи } 0^{\circ} \text { та опер. } \\
\text { ділянки, см }(\mathrm{n}=14)\end{array}$ & $\begin{array}{l}(\mathrm{M} \pm \mathrm{SD}) \\
\text { Min-max }\end{array}$ & $\begin{array}{c}3,41 \pm 0,478 \\
2,7-4,1\end{array}$ & - & - & $\begin{array}{c}3,81 \pm 0,52 \\
3,5-4,3\end{array}$ & - & - \\
\hline $\begin{array}{l}\text { Дистанція між } \\
\text { лапароск з кутом } \\
\text { лінзи } 30^{\circ} \text { та опер. } \\
\text { ділянки, см. }(\mathrm{n}=14)\end{array}$ & $\begin{array}{l}(\mathrm{M} \pm \mathrm{SD}) \\
\text { Min-max }\end{array}$ & $\begin{array}{c}3,34 \pm 0,728 \\
2,5-4,5\end{array}$ & - & - & $\begin{array}{c}3,64 \pm 0,36 \\
3,3-4,0\end{array}$ & - & - \\
\hline
\end{tabular}

Примітки: 1. **. Кореляція значуща на рівні 0,01 (2-tailed).

2. $\mathrm{M} \pm \mathrm{SD}$ - середнє значення \pm стандартне відхилення середнього.

3. Min-max - мінімальне-максимальне значення.

що при нормостенічному варіанті статури кут між основними робочими інструментами при власному способі встановлення портів для операції в середньому становить $(74,43 \pm 8,112){ }^{\circ}$ [66-83] ${ }^{\circ}$ та $є$ більшим порівняно з середнім значенням кута при французькому способі - $(57,29 \pm 6,764){ }^{\circ}[44-$ $65]^{\circ}\left(\mathrm{p}<0,001^{*}\right)$, хоча обидва способи мають спільні точки локалізації портів, призначених для основного маніпулятора та лапароскопа, а відрізняються лише локалізацією допоміжних портів. При цьому площа візуалізації при порівнянні значень нормостенічного варіанту для власного способу в середньому становить $(15,24 \pm 3,76)$ см$^{2}$ та є більшою порівняно з показником французького способу $(9,54 \pm 2,27) \mathrm{cm}^{2}\left(\mathrm{p}<0,001^{*}\right)$.

Порівняння параметрів власного способу з параметрами решти способів симультанних операційних втручань проведено шляхом дисперсійного аналізу з повторними вимірюваннями.

При порівнянні оцінених маргінальних середніх значень площі зони візуалізації власного способу - $(15,24 \pm 3,76) * * \mathrm{~cm}^{2}(\mathrm{n}=42)$ та французького способу ЛХ - $(9,54 \pm 2,27)^{* *} \mathrm{~cm}^{2}(\mathrm{n}=42)$ виявлено статистично значущу різницю $(\mathrm{p}=0,715)$.

\footnotetext{
* - тест для парних вибірок; ** $-\mathrm{M} \pm \mathrm{SD}$ - значення \pm стандартна похибка середнього.
} 
При застосуванні лапароскопа 3 кутом спостереження $0{ }^{\circ}$ відстань наближення лапароскопа при власному способі доступу в середньому становить $(3,81 \pm 0,52)$ см $[3,5-4,3]$ см та $є$ достовірно більшою порівняно з французьким способом, середнє значення досліджуваного параметра становить - $(3,41 \pm 0,478)$ см $[2,7-4,1]$ см $(\mathrm{p}<0,001)$ (рис. 1). Відстань наближення лапароскопа при власному способі доступу в середньому становить $(3,64 \pm 0,36)$ см $[3,3-4,0]$ см та $є$ достовірно більшою порівняно з французьким способом, середнє значення досліджуваного параметра становить $(3,34 \pm 0,728)$ см $[2,5-4,5]$ см $(\mathrm{p}<0,001)$.

Тому з огляду на деталізацію зображення, ширину огляду, панорамність огляду ефективнішим $\epsilon$ розроблений спосіб симультанних операційних втручань, адже при достатньому наближенні до об'єкта операції зменшується ймовірність по- шкоджень структур гепатодуоденальної зв'язки, пов'язаних із недостатньою візуалізацією, а достатня при цьому панорамність дозволяє контролювати рух маніпуляторів.

Окрім того, встановлено, що застосування лапароскопа з кутом спостереження $30^{\circ}$ для французького та власного способів симультанного операційного лікування забезпечує більш оптимальні умови порівняно з лапароскопом, кут спостереження якого становить $0^{\circ}$.

Таким чином, враховуючи показник доступності до об'єкта операції, можливості деталізації структур при умовах, коли маніпуляції обмежені у зв’язку з набряком тканин та їх щільністю, що знижує піддатливість останніх, найоптимальнішим методом симультанних операційних втручань при гострих хірургічних патологіях $є$ власний спосіб.

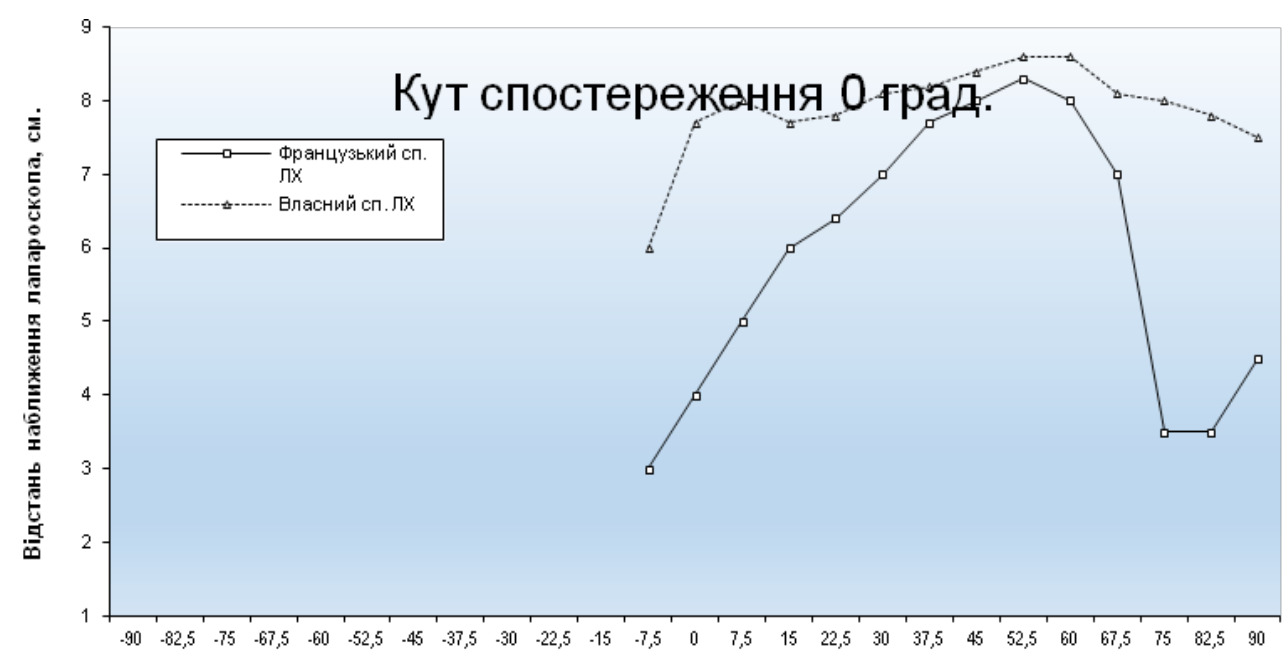

Кут положення осі цільового органа при симультанних операційних втручаннях

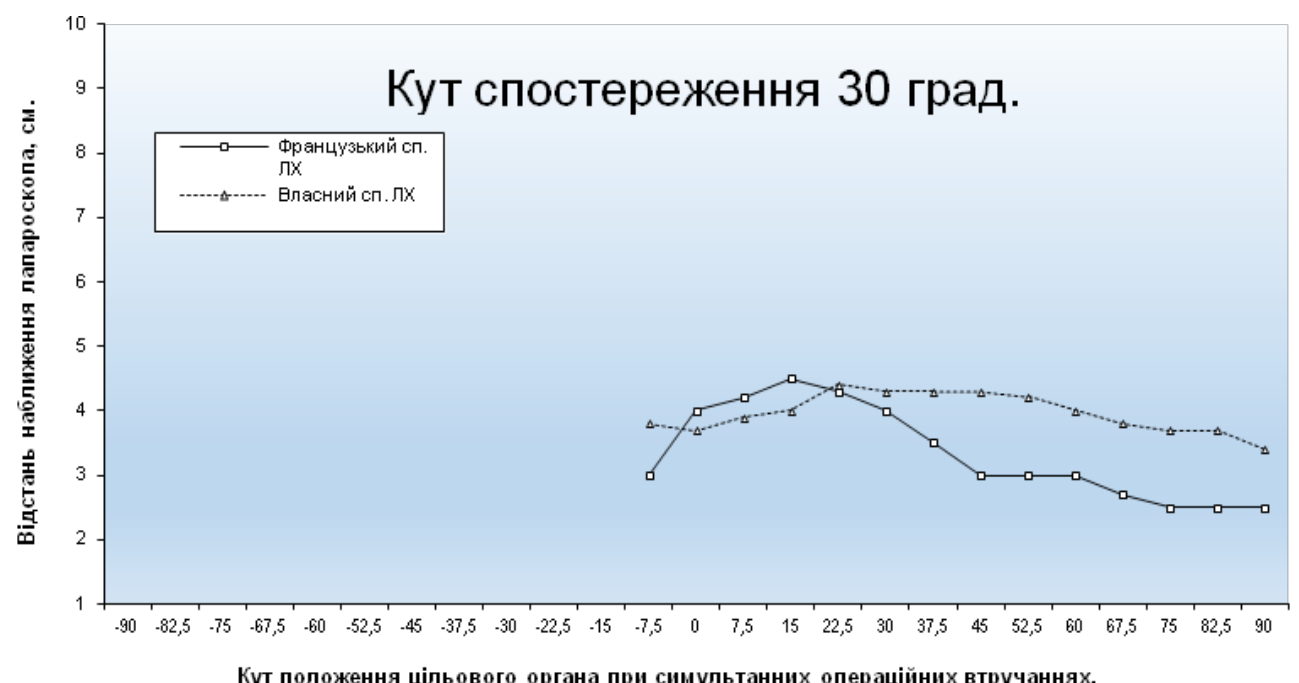

Рис. 1. Показники відстані наближення ендоскопа для кожного зі способів симультанних операцій при застосуванні лапароскопів з кутом спостереження $0^{\circ}$ та $30^{\circ}$. 
Висновки. 1. Розроблені нові критерії вивчення параметрів операційного доступу (які доповнюють загальноприйняті положення про операційний доступ в ендохірургії та характеризують ергономічні особливості маніпуляцій інструментами і враховують обмеження доступності до об'єкта втручання) у поєднанні з відомими параметрами забезпечили можливість для порівняння власного способу 3 французьким способом симультанних операційних втручань за якістю доступу і ергономічними умовами виконання операції при різних хірургічних патологіях, виключно гострі.

2. За результатами дослідження встановлено, що оцінене маргінальне середнє значення площі зони візуалізації при власному способі симультанних операційних втручань становить $(15,24 \pm 3,76)$ см $^{2}$ та $є$ більшим на 62,6 \% від відповідного показника французького способу - $(9,54 \pm 2,27)$ см $^{2}(\mathrm{p}=0,715)$.

3. При застосуванні лапароскопа з кутом спостереження $0^{\circ}$ відстань наближення лапароскопа при власному способі доступу в середньому становить $(3,81 \pm 0,52)$ см та $є$ більшою на 10,5 \% порівняно 3 середнім значенням досліджуваного параметра при французькому способі $(3,41 \pm 0,478)$ см $(\mathrm{p}=0,295)$.

\section{СПИСОК ЛІТЕРАТУРИ}

1. European Society of Gastrointestinal Endoscopy. Prophylaxis of post-ERCP pancreatitis: European Society of Gastrointestinal Endoscopy (ESGE) Guideline - updated / J. M. Dumonceau, A. Andriulli, B. J. Elmunzer [et al.] // Endoscopy. - 2014. Vol. 46. - P. 799-815.

2. GallRiks. Annual report 2016. [Electronic resource]. - Mode access : http://www.ucr.uu.se/gallriks/fou/arsrapporter [accessed 31 May 2018]

3. Freeman M. L. Post-ERCP pancreatitis: patient and techniquerelated risk factors / M. L. Freeman // JOP. - 2002. - Vol. 3. P. 169-176.

4. Risk factors for post-ERCP pancreatitis: a systematic review of clinical trials with a large sample size in the past 10 years / J. J. Chen, X. M. Wang, X. Q. Liu [et al.] // Eur. J. Med. Res. - 2014. - Vol. 15. - P. 19-26.

5. Incidence rates of post-ERCP complications: a systematic survey of prospective studies / A. Andriulli, S. Loperfido, G. Napolitano [et al.] // Am. J. Gastroenterol. - 2007. Vol. 102 (8). - P. 1781-1788.

6. Cotton Peter B. (2013-05-31). ERCP (Endoscopic Retrograde Cholangio-Pancreatography) / B. Cotton Peter // Medical University of South Carolina (MUSC) Digestive Disease Center.

\section{REFERENCES}

1. Dumonceau, J.M., Andriulli, A., Elmunzer, B.J., Mariani, A., Meister, T., Deviere, J., Marek, T., Baron, T.H., Hassan, C., Testoni, P.A., \& Kapral, C. (2014). European Society of Gastrointestinal Endoscopy. Prophylaxis of post-ERCP pancreatitis: European Society of Gastrointestinal Endoscopy (ESGE) Guideline - updated June 2014. Endoscopy, 46, 799-815.

2. GallRiks. Annual report 2016. Retrieved from : http://www. ucr.uu.se/gallriks/fou/arsrapporter [accessed 31 May 2018]
4. При застосуванні лапароскопа з кутом спостереження $30^{\circ}$ відстань наближення лапароскопа при власному способі доступу в середньому становить $(3,64 \pm 0,36)$ см та $є$ більшою на 9,12 \% порівняно з показником французького способу $(3,34 \pm 0,728)$ см $(\mathrm{p}<0,001)$.

Таким чином, отримані нові дані, які підтверджують гіпотезу про те, що досліджувані способи виконання симультанних операційних втручань відрізняються за доступністю до об’єкта операції та можливостями візуалізації. Також дані свідчать, що власний спосіб лікування калькульозного холециститу і супутньої хірургічної патології, з огляду на досліджувані параметри, $є$ оптимальнішим порівняно 3 класичними французьким способом.

У підсумку власний спосіб забезпечує підвищення безпеки маніпуляцій при виконанні лапароскопічної холецистектомії симультанно в умовах гострого і хронічного холециститу за рахунок кращої доступності до об'єкта операції, меншого фізичного навантаження та відповідно емоційного напруження хірурга, що зменшує ймовірність помилки при виконанні операції.

7. Sharon Begley. FDA knew devices spread fatal 'superbug' but does not order fix / Sharon Begley, Toni Clarke // Reuters. - 2015. - Mode access : https://www.cochranelibrary.com/cdsr/ doi/10.1002/14651858.CD007345.pub2/full

8. Antibiotic prophylaxis for patients undergoing elective endoscopicretrogradecholangiopancreatography/M.Brand,D.Bizos, P. O'Farrell // The Cochrane Database of Systematic Reviews. 2010. - (10). CD007345. doi:10.1002/14651858.CD007345. pub2. PMID 20927758.

9. https://www.nature.com/articles/ajg2007345

10. https://journals.sagepub.com/doi/

pdf/10.1177/145749690509400108

11. http://www.mif-ua.com/archive/article/35421

12. Досвід лапароскопічних операцій у хворих на жовчнокам'яну хворобу / Ю. С. Семенюк, О. В. Потійко, І. В. Сидорук [та ін.] // Шпитальна хірургія. Журнал імені Л. Я. Ковальчука. - 2015. - № 3. - С. 33-35.

13. Simultant laparoscopic operations for biliocalculous disease and hernia of anterior abdominal wall / M. Yu. Nichitaylo, İ. S. Zagriychuk, Yu. I. Bulyk [et al.]. 616.366—003.7+617.55007.43]—072.1—089.819

3. Freeman, M.L. (2002). Post-ERCP pancreatitis: patient and technique-related risk factors. JOP, 3, 169-176.

4. Chenk, J.J., Wang, X.M., Liu, X.Q., Li, W., Dong, M., Suo, Z.W., Ding, P., \& Li, Y. (2014). Risk factors for post-ERCP pancreatitis: a systematic review of clinical trials with a large sample size in the past 10 years. Eur. J. Med. Res.. 15, 19-26.

5. Andriulli, A., Loperfido, S., Napolitano, G., Niro, G., Valvano, M.R., Spirito, F., Pilotto, A., \& Forlano, R. (2007). 
Incidence rates of post-ERCP complications: a systematic survey of prospective studies. Am. J. Gastroenterol., 102 (8), 1781-1788. 6. Cotton, Peter B. (2013-05-31). ERCP (Endoscopic Retrograde Cholangio-Pancreatography). Medical University of South Carolina (MUSC) Digestive Disease Center.

7. Sharon Begley; Toni Clarke (2015). FDA knew devices spread fatal 'superbug' but does not order fix. Reuters.

8. doi/10.1002/14651858.CD007345.pub2/full

9. Brand, M., Bizos, D., \& O'Farrell P. (2010). Antibiotic prophylaxis for patients undergoing elective endoscopic retrograde cholangiopancreatography. The Cochrane Database of Systematic Reviews, (10). CD007345. doi:10.1002/14651858. CD007345.pub2. PMID 20927758.

10. https://www.nature.com/articles/ajg2007345

11. https://journals.sagepub.com/doi/ pdf/10.1177/145749690509400108

12. Semeniuk, Yu.S., Potiiko, O.V., Sydoruk, I.V., Ordynskyi, Yu.M., Fedoruk, V.A., Minich, V.H., Lepekha, V.B., Andrushkiv, N.M. (2015). Dosvid laparoskopichnykh operatsii u khvorykh na zhovchnokamianu khvorobu [Experience of laparoscopic surgery in patients with cholelithiasis]. Shpytalna khirurhiia - Hospital Surgery. Journal named after L. Ya. Kovalvhuk, 3, 33-35 [in Ukrainian].

13. Nichitaylo M. Yu., Zagriychuk, I.S., \& Bulyk, Yu. I. Simultant laparoscopic operations for biliocalculaus disease and hernia of anterior abdominal wall.

Отримано 21.12.2018

Електронна адреса для листування: vodoo.lsmu@gmail.com

\title{
M. YU. NYCHITAYLO ${ }^{1}$, M. M. HALEI ${ }^{2}$, O. I. DZIUBANOVSKYI ${ }^{3}$
}

O. Shalimov National Institute of Surgery and Transplantation ${ }^{1}$

I. Horbachevsky Ternopil State Medical Univerity ${ }^{2}$

Volyn Regional Clinical Hospital ${ }^{3}$

\section{COMPARATIVE EVALUATION OF THE EFFECTIVENESS OF ONE-STAGE LAPAROSCOPIC TREATMENT OF GALLSTONE DISEASE AND ASSOCIATED SURGICAL PATHOLOGY}

\begin{abstract}
The aim of the work: to find out the most effective visualization technique for performing laparoscopic surgical treatment of gallstone disease and collateral surgical pathology

Materials and methods. A retrospective analysis of 411 patients with gallstone disease and collateral surgical pathology. For processing the statistic data zero hypothesis was used. For comparing visualization zone was measured. French and proper methods of performing cholecystectomy were compared.

Results and Discussion. According to research results middle marginal definition of visualization area in proper method of performing simultaneous operations was $(15.24 \pm 3.76) \mathrm{cm}^{2}$, which is more on $62.6 \%$ in compared French method $-(9.54 \pm 2.27) \mathrm{cm}^{2}(\mathrm{p}=0.715)$.

If $0^{\circ}$ laparoscope was used, approximation distance was $(3.81 \pm 0.52) \mathrm{cm}$ in proper method, which is more on $10.5 \%$ comparing to the same index in French method $(3.41 \pm 0.478) \mathrm{cm}(\mathrm{p}=0.295)$. If $30^{\circ}$ laparoscope was used, approximation distance was $(3.64 \pm 0.36) \mathrm{cm}$ in proper method, which is more on $9.12 \%$ comparing to the same index in French method - $(3.34 \pm 0.728) \mathrm{cm}(\mathrm{p}<0.001)$.
\end{abstract}

Key words: surgery; cholecystectomy; gallstone disease; laparoscopy; simultaneous interventions.

\author{
М. Е. НИЧИТАЙЛО ${ }^{1}$, Н. М. ГАЛЕЙ², О. И. ДЗЮБАНОВСКИЙ ${ }^{3}$
}

Национальный институт хирургии и трансплантологии имени А. А. Шалимова ${ }^{1}$

Волынская областная клиническая больница

ГВУЗ “Тернопольский государственный медицинский университет имени И. Я. Горбачевского МОЗ Украины”з

\section{СРАВНИТЕЛЬНАЯ ОЦЕНКА ЭФФЕКТИВНОСТИ РАЗРАБОТАННОГО ОДНОМОМЕНТНОГО ЛАПАРОСКОПИЧЕСКОГО ЛЕЧЕНИЯ ЖЕЛЧНОКАМЕННОЙ БОЛЕЗНИ И СОПУТСТВУЮЩЕЙ ХИРУРГИЧЕСКОЙ ПАТОЛОГИИ}

\begin{abstract}
Цель работы: опредилить максимально эффективную технологию визуализации для лапароскопического операционного лечения желчнокаменной болезни (ЖКБ) и сопутствующей хирургической патологии.

Материалы и методы. Использовали статистические данные лечения 411 больных ЖКБ и сопутствующей хирургической патологией. Для обработки статистики использовались методы с нулевой гипотезой. Для сравнения измеряли зону визуализации. Для сравнения использовали собственный метод и французкий метод выполнения лапароскопической холецистэктомии. Результаты исследований та их обсуждение. По результатам исследований установлено среднее маргинальное значение площади зоны визуализации при собственном методе симультанных операционных вмешательств, а именно $(15,24 \pm 3,76)$ см², что больше на 62,6 \% за соответствующий показатель у французкого способа - $(9,54 \pm 2,27)$ см² $^{2}(\mathrm{p}=0,715)$; при использовании лапароскопа с углом наблюдения $0{ }^{\circ}$ расстояние приближения лапароскопа при собственном методе доступа в среднем составляет $(3,81 \pm 0,52)$ см и больше 10,5 \% в сравнении со середним значением исследуемого параметра при французком способе $(3,41 \pm 0,478)$ см (p=0,295); при использовании лапароскопа с углом наблюдения $30{ }^{\circ}$ расстояние приближения лапароскопа при собственном методе доступа в среднем составляет $(3,64 \pm 0,36)$ см и больше на 9,12 \% в сравнении со середним значением исследуемого параметра при французком способе - $(3,34 \pm 0,728)$ см $(\mathrm{p}<0,001)$.
\end{abstract}

Ключевые слова: хирургия; холецистэктомия; желчнокаменная болезнь; лапароскопия; симультанные вмешательства. 